\section{Life satisfaction of Paralympians: The role of needs satisfaction and passion}

\author{
Filipe Rodrigues ${ }^{1,2}\left({ }^{(}\right.$, Geneviève A. Mageau $^{3}$, Emilie Lemelin ${ }^{3}$, \\ Diogo Teixeira ${ }^{4}$, Anabela Vitorino ${ }^{1,5}$, Luís Cid ${ }^{1,5}$ and \\ Diogo Monteiro ${ }^{5,6}$ (1)
}

International Journal of Sports Science \& Coaching $0(0)$ I-9

(C) The Author(s) 2021

Article reuse guidelines: sagepub.com/journals-permissions DOI: $10.1177 / 17479541211036224$ journals.sagepub.com/home/spo

@SAGE

\begin{abstract}
The current study examined the possible role of basic psychological needs and passion in Paralympians' life satisfaction. A mediational model was tested where autonomy, competence and relatedness were hypothesized to be linked to athlete life satisfaction via harmonious and obsessive passion. The sample comprised 9l Portuguese Paralympians aged between 18 and 59 years $(M=31.0 \mathrm{I} ; S D=3.78)$. Athletes completed self-reports of needs satisfaction in their sport, passion towards their sport, and general life satisfaction. Perceptions of competence and relatedness were associated with harmonious passion $(\beta=.37, p>.01 ; \beta=.21, p>.05$, respectively), while perceptions of autonomy were associated with obsessive passion $(\beta=.39, \mathrm{p}>.05)$. Additionally, harmonious passion, but not obsessive passion, was associated with life satisfaction $(\beta=.40, \mathrm{p}>.0 \mathrm{I})$, and only the indirect effect from competence to life satisfaction, via harmonious passion, was significant. These results suggest that feeling autonomous may not necessarily translate into more harmonious passionate engagement but is associated with higher levels of obsessive passion. In contrast, competence and relatedness appear to play an important role in the life of athletes who experience a more harmonious passion towards their sport practice. Perceptions of mastery and competence, as well as sport-related social connections could be important to consider improving the lives of athletes with Paralympic experience.
\end{abstract}

\section{Keywords}

Life satisfaction, needs satisfaction, Paralympians, passion
Past literature has shown that daily physical activity increases individual physical fitness and can also lead to increased achievement and self-esteem, enabling higher life satisfaction. ${ }^{1}$ For athletes with physical or mental disabilities, it is even more important to be physically active to maintain physical performance and to perceive control over their own behavior as a means to experience well-being. ${ }^{2}$

Participation in sports could promote life satisfaction because it represents an avenue to meet psychological needs as well as to express oneself and integrate social groups. ${ }^{3}$ As such, sports often become part of people's identity and may be described as passions. ${ }^{2,4}$ This may be particularly the case for athletes with disabilities, such as Paralympians, as active sport engagement is pursued despite several obstacles (e.g., transportation, accommodations, and adjusted equipment). Although needs satisfaction and passion towards sports may be particularly relevant for athletes with mental and/or physical disabilities, especially those who have international and Olympic competitive

Reviewers: Robert J. Vallerand, Université du Québec à Montréal, Canada Thais Benoit, University of Merced, USA

'Sport Science School of Rio Maior (ESDRM-IPSantarém), Rio Maior, Portugal

${ }^{2}$ Life Quality Research Center (CIEQV), Santarém, Portugal

${ }^{3}$ Université de Montréal, Montréal, Canadá

${ }^{4}$ University of Lusófona, Lisbon, Portugal

${ }^{5}$ Research Center in Sport, Health and Human Development (CIDESD), Vila Real, Portugal

${ }^{6}$ ESECS, Polytechnique of Leiria, Leiria, Portugal

Corresponding author:

Filipe Rodrigues, Av. Dr. Mário Soares nI I0, 2040-4I3 Rio Maior, Portugal.

Email: ptfiliperodrigues@gmail.com 
experience, no research has yet investigated how these variables relate to these athletes' life satisfaction. The present research examined how needs satisfaction relates to passion and, ultimately, to life satisfaction ${ }^{5}$ in a sample of Paralympian athletes, with the goal of guiding athletes with mental and/or physical disabilities towards more passionate and positive forms of sport engagement.

\section{Basic psychological needs theory}

Basic psychological needs theory ${ }^{6}$ proposes that all human beings have three innate needs, namely the need for autonomy, competence, and relatedness, whose satisfaction is essential for psychological wellness and optimal functioning. Autonomy refers to the need to have a sense of volition and self-endorsement over one's behaviors. Competence assumes that individuals seek, and benefit from, having control over specific outcomes and experiencing a sense of mastery. Relatedness refers to the notion that all human beings need to form positive social relationships as well as experience social connections and a sense of caring for others. Satisfaction of these three needs has been repeatedly associated with positive outcomes such as intrinsic motivation, subjective well-being, life satisfaction, and other health-related behaviors. ${ }^{6}$ Furthermore, previous research has demonstrated that these needs are also associated with passion, ${ }^{7,8}$ suggesting that autonomy, competence, and relatedness satisfaction could be key in both the development of passion and the experience of life satisfaction.

\section{The dualistic model of passion}

The Dualistic Model of Passion (DMP) ${ }^{9}$ defines passion as a strong inclination towards an activity that one likes, finds important, and in which one invests time and energy. The DMP proposes two different types of passion that can develop depending on the way the activity has been internalized, namely harmonious and obsessive passion.

Harmonious passion (HP) results from an autonomous internalization, ${ }^{6}$ which occurs when the individuals spontaneously value and identify with the activity without experiencing additional pressures or external contingencies. ${ }^{10}$ In other words, HP is experienced when the activity is freely accepted as important and self-defining by the individual. HP driven individuals thus consider their activity as an integral part of themselves, which occupies a significant but not overwhelming space in the person's identity and personal life.

In contrast, obsessive passion (OP) may result from a controlled internalization of the activity into one's identity, ${ }^{10}$ meaning that the activity could be attached to external or internal contingencies that prompt engagement (e.g., self-esteem contingencies). ${ }^{11}$ Yet, athletes who experience OP still deeply love their activity, which may perhaps explain their tendency to overengage in their sport and rigidly persist in their training despite injuries or other obstacles. ${ }^{8,12}$

Past literature shows that HP is associated with more adaptive processes and outcomes such as wellbeing or life satisfaction, ${ }^{4,73}$ while OP rather relates to maladaptive ones, such as negative activations, burnout, and withdrawal from sport practice. ${ }^{9}$ This pattern of associations suggests that promoting passion in athletes is not enough to promote a heightened sense of satisfaction, particular care must be invested in nurturing a more harmonious rather than an obsessive form of sport engagement. Yet, literature regarding the key factors within the passionate activity shown to predict passion, namely needs satisfaction, does not seem to differentiate between HP and OP.

\section{The association between needs satisfaction and passion}

Past research shows that needs satisfaction experienced within the passionate activity may be positively related to each type of passion and these findings have been observed in a variety of activities and behaviors such as music, work, basketball, running, and in general across samples. ${ }^{7,13}$ Yet, Tóth-Király et al., ${ }^{14}$ in two studies, found that in a leisure context, needs satisfaction was not significantly associated with HP but rather was negatively related to OP. The positive relation between needs satisfaction within the passionate activity and OP observed by Lalande et al. ${ }^{7}$ is also contradictory with past and contemporary research ${ }^{15}$ where OP is typically related to negative outcomes. These conflicting findings may result from the fact that past studies on the positive relation between needs satisfaction and the two types of passion have investigated needs satisfaction using a global score, which may blur important distinctions in the relations between the three needs and the two types of passion.

Looking at needs separately, a different pattern of results may indeed be expected. Research on the central role of autonomy for the internalization process ${ }^{6}$ first suggests that perceptions of autonomy should be associated differentially with HP and OP. Past studies also shows that people with HP report more autonomy support from significant social agents than people experiencing OP ${ }^{16}$ which suggests that perceptions of autonomy could be uniquely related to HP. ${ }^{17}$ Yet, it is still possible that autonomy experiences within the activity may be a prerequisite for experiencing any form of passion. After all, both HP and OP driven 
individuals report high intrinsic motivation toward their passionate activity. ${ }^{18}$

In contrast, perceptions of competence and relatedness should be related to both types of passion. On one hand, having a sense of mastery over one's sport and feeling connected to others should be requirements to experiencing any form of passion, especially HP. ${ }^{18}$ Yet, perceptions of competence and relatedness could also predict OP because high competence and feeling deeply valued in a particular activity may tempt people to derive part of their self-worth from this activity, which in turn could set the stage for the development of a more obsessive passion (see Mageau et al. ${ }^{11}$ ).

Considering that each need may have differentiated effects on motivational processes ${ }^{6}$ and that high satisfaction of one need cannot compensate for thwarting experiences in the others, ${ }^{19}$ attending to the unique relation between each need and the two types of passion is warranted.

\section{Passion as mediator of the link between needs satisfaction and life satisfaction}

Moreover, despite receiving considerable attention in motivational research, ${ }^{20}$ few studies have examined how needs satisfaction and passion could translate into athletes' life satisfaction. Lalande et al. $^{7}$ proposed a mediation model where needs satisfaction predict passion, which in turn predicts life satisfaction. Results suggest that needs satisfaction (measured together) indirectly predict life satisfaction only via HP; OP was either unrelated or negatively related to life satisfaction. ${ }^{7}$ Yet, as it was the case for the association between needs satisfaction and passion, this mediation model was never examined while considering the different types of needs. Given that passion may be a motivational process that is dependent on needs satisfaction, it is postulated that passion, especially HP, could mediate the relations between the individual needs and life satisfaction.

\section{Alternative model: Needs satisfaction as mediator of the passion-life satisfaction link}

Given that passion can manifest itself in different ways, reflecting the way the activity has been internalized in athletes' identity, ${ }^{21}$ previous studies have tested its influence on needs satisfaction, which in turn was modeled to predict life satisfaction. ${ }^{8,22}$ For example, Kent et al. ${ }^{22}$ have shown HP to have a positive and significant effect on all needs, whereas OP seems to be unrelated or negatively related to autonomy, competence, and relatedness satisfaction. In contrast, Lopes and Vallerand ${ }^{8}$ found positive prediction of OP and HP on needs satisfaction in sport using a global measure of needs satisfaction. It thus seems possible that a bidirectional link exists between needs satisfaction and passion. While needs satisfaction may influence motivational processes (e.g., passion), the type of passion may also determine the degree of needs satisfaction that athletes will derive from their activity. Accordingly, an alternative model will be tested, where needs satisfaction will be considered as a mediator of the relations between the two types of passion and life satisfaction.

\section{Current research}

The purpose of the current study is to examine the hypothesis that passion can play an important role in the association between needs satisfaction and life satisfaction in Paralympians. This study will add to previous research in sport and exercise psychology, as it considers the association between each individual need and each type of passion. Previous studies that have collected data with athletes have rather assumed that needs should operate as one unifying factor. ${ }^{7,8}$

Importantly, we will examine the relations between needs, passions, and life satisfaction in an underresearch group but for whom passion is likely to be of the upmost importance, that is Paralympians. Indeed, these athletes, despite facing daily challenges to their sport participation related to their disabilities, have sustained the high and long-term engagement necessary to qualify for competing in international sports events, suggesting that high levels of passion may be at play for many of these athletes.

We hypothesized that Paralympian perceptions of all three needs would be positively associated with HP but that only perceptions of competence and relatedness would predict OP. Moreover, we predicted that HP, but not OP, would be positively associated with life satisfaction in Paralympians. Finally, based on past research showing how needs satisfaction may influence motivational processes, ${ }^{6}$ we expected that the indirect associations between needs satisfaction and satisfaction of life via passion would be significant for HP only, and that the proposed alternative model, where passion would be associated with life satisfaction via needs satisfaction, would have a poorer fit to the data.

\section{Methods}

\section{Participants}

The sample comprised of 91 Portuguese Paralympians (women $=22$; men $=69$ ) aged between 15 and 59 years $(M=31.01 ; S D=9.71)$. Mental and physical disabilities were identified as cerebral palsy $(n=25)$, visual deficiency $(n=20)$, motor deficiency $(n=37)$, hearing deficiency $(n=5)$ intellectual deficiency $(n=2)$, and other type $(n=2)$. A range of individual and team 
sports were represented, for example: swimming $(n=22)$, tricycle $(n=10)$, football 7 a side $(n=7)$, wheelchair basketball $(n=3)$, and boccia $(n=16)$. Athletes trained on average 4.50 sessions per week $(S D=2.71$ sessions) and had been involved in their sport for an average of 8.57 years $(S D=3.71$ years). The inclusion criterion to participate in this study was to have competed in at least one of the four previous Paralympic Games (i.e., 2016 - Rio de Janeiro; 2012 - London; 2008 - Beijing; 2004 - Athens).

\section{Procedures}

Before data collection, the study was reviewed and approved by the Ethical Committee. Data collection procedures were carried out according to the Helsinki declaration and its later amendments, and all participants completed an informed consent form. The study included two phases. First, through the Paralympic committee databases, potential participants were screened and contacted individually during pre-season. For the second phase, athletes who accepted to partake to this study signed an informed consent form before completing the online questionnaire, alone when possible. Athletes who were unable to complete the questionnaires on their own received assistance from their coach or from a family member, according to athletes' preference. Researchers informed athletes and their assisting persons (if applicable) that there was no good or bad answer to each question and athletes should respond according to their own experiences. When athletes required assistance, their coach or family member were instructed to read each question aloud, record athletes' responses, and repeat each question to double check and confirm each response. We asked assisting persons not to comment or influence athletes' answers and stressed the importance of preserving participant confidentiality. No missing responses were present because the online survey required athletes to provide an answer to proceed in the survey. Athletes received no compensation for their participation.

\section{Measures}

Basic psychological needs satisfaction. The Portuguese version of the Basic Psychological Need Exercise Scale adapted to the sport context ${ }^{23}$ was used to assess levels of autonomy (four items; sample item: "I feel that I play sports the way I want to."; $\alpha=.65$ ), competence, (four items; sample item: "I am able to meet the requirements of my training program."; $\alpha=.72$ ) and relatedness (four items; sample item: "The people with whom I train are very friendly."; $\alpha=.82$ ) satisfaction. Responses were provided on a 5 -point Likert scale $(1=I$ do not agree at all to $5=$ I completely agree).
Passion. The Portuguese version of the 8-item Passion Scale ${ }^{24}$ was used to assess the degree of HP (four items; sample item: "This sport is in harmony with other things that are part of me") and OP (four items; sample item: "I have almost an obsessive feeling for this activity") athletes experience during sport practice $(\alpha=.73$ for HP, $\alpha=.88$ for OP). Participants rated each statement using a 7 -point scale $(1=$ totally disagree to $7=\mathrm{I}$ totally agree).

Life satisfaction. The Portuguese version of the Life satisfaction Scale $^{25}$ was used to measure athlete global evaluation of their life satisfaction (sample item: "I am satisfied with my life."; $\alpha=.84$ ). Participants indicated their levels of agreement with each of the 5 items using a 7 -point scale $(1=I$ do not agree at all to $5=I$ completely agree).

\section{Analyses plan}

Means, standard deviations, normal distribution indicators, and correlations were computed for all study variables. Cutoffs for normality were determined based on existing guidelines; ${ }^{26}$ accepting scores were within $-2 /+2$ and $-7 /+7$ for skewness and kurtosis, respectively. The presence of outliers was also verified. Next, we performed ANOVAs to test for any differences between men and women and types of sports (individual vs. team sports) on passion, needs and life satisfaction. If significant differences were to emerge, we planned to include these variables as covariables. Finally, path analyses were conducted with AMOS VERSION $25.0^{27}$ to test the proposed and alternative model, while controlling for the number of weekly training sessions. We considered training volume as a covariable because of its documented impact on both types of passion. ${ }^{8}$ For model fit, we examined several traditional and incremental indices, specifically: Comparative Fit Index (CFI), Tucker-Lewis Index (TLI), model's chi-square statistic $\left(\chi^{2}\right)$, Standardized Root Mean Square Residual (SRMR), and Root Mean Square error of Approximation (RMSEA). For the CFI and TLI, values exceeding .90, and a nonsignificant chi-square statistic are typically interpreted to reflect acceptable fit. RMSEA values are recommended to be below .05. The upper bound of their confidence intervals should not exceed .08 and the close-fit test should be non-significant (i.e., RMSEA should not differ significantly from a .05 value). ${ }^{28}$

\section{Results}

\section{Preliminary analyses}

Descriptive statistics, and the correlation matrix are reported in Table 1. Results displayed no violations 
Table I. Descriptive statistics and correlations.

\begin{tabular}{|c|c|c|c|c|c|c|c|c|c|c|}
\hline & $M$ & $S D$ & $\mathrm{~S}$ & $\mathrm{~K}$ & $\mathrm{I}$. & 2. & 3. & 4. & 5. & 6. \\
\hline I. Autonomy & 4.05 & .55 & -.24 & -.05 & I & & & & & \\
\hline 2. Competence & 4.19 & .47 & -.001 & -.27 & $.62 * *$ & I & & & & \\
\hline 3. Relatedness & 4.42 & .50 & -.61 & .48 & $.34^{*}$ & $.30 * *$ & 1 & & & \\
\hline 4. Harmonious passion & 6.19 & .65 & -.57 & -.42 & $.24^{*}$ & $.39 * *$ & $.30 * *$ & I & & \\
\hline 5. Obsessive passion & 5.02 & 1.21 & -.31 & -.40 & $.43^{* *}$ & $.38^{* *}$ & $.24 *$ & $.38 * *$ & I & \\
\hline 6. Satisfaction with life & 5.18 & .96 & -.25 & .18 & $.25^{*}$ & $.23 * *$ & $.22^{*}$ & $.35^{*}$ & $.24 *$ & I \\
\hline
\end{tabular}

Notes: $M=$ Mean; $S D=$ Standard Deviation; $S=$ Skewness; $K=$ Kurtosis. $* p<.05, * * p<.01$.

of the univariate distribution since skewness and kurtosis were contained between -2 and +2 , and -7 and +7 , respectively. Additionally, one outlier was found. This extreme score was transformed into scores no further than 3.29 standard deviations from the sample mean. ${ }^{29}$ There was no missing data in this sample. Descriptive statistics revealed that mean scores for all variables were above the scale mid-point. All variables were positively and significantly correlated to each other. Moreover, ANOVAs did not reveal any difference between genders or types of sport (individual vs. team sports) on all main variables $(p s \geq .25)$. Gender and types of sport were thus not considered as covariables.

\section{Main analyses}

Proposed Model. The proposed model (see Figure 1), where autonomy, relatedness and competence are associated with HP and OP, which are in turn linked to life satisfaction while controlling for weekly training sessions, showed good fit indices, $\chi^{2}(3)=2.56, p=.46$, $\mathrm{TLI}=1.02, \mathrm{CFI}=1.00, \quad \mathrm{SRMR}=.03, \quad \mathrm{RMSEA}=.00$ $[.00, .17]$, PCLOSE $=.56$. Beta coefficients showed that competence and relatedness were associated with HP ( $\beta=.38, p=.002 ; \beta=.21, p=.05$ respectively), but not with $\mathrm{OP}(p \mathrm{~s} \geq .20)$. Conversely, autonomy was associated with OP $(\beta=.28, p=.02)$, but not with HP $(p=.66)$. Finally, only HP was associated with life satisfaction $(\beta=.30, p=.004 ; p=.22$ for OP). Indirect effects were significant for competence (IC95\% $=[.03$, $.26], p=.02$ ), marginal for relatedness (IC95\% $=[-.02$, $.19], p=.11)$, but non-significant for autonomy $(\mathrm{IC} 95 \%=[-.11, .16], \quad p=.76)$. Effect sizes were between medium and large for OP $\left(R^{2}=.22\right)$, HP $\left(R^{2}=.20\right)$ and life satisfaction $\left(R^{2}=.14\right){ }^{30}$

Alternative Model. Since this study is not experimental, directionality of observed relations cannot be attested. Accordingly, we tested an alternative model, where OP and HP were directly linked to the three needs, which in turn were associated with life satisfaction while controlling for weekly training sessions. This model showed poor fit indices, $\chi^{2}(2)=3.72, p=.02$, $\mathrm{TLI}=.47, \quad \mathrm{CFI}=.95, \quad \mathrm{SRMR}=.05, \quad \mathrm{RMSEA}=.17$ $[.05, .32], \mathrm{PCLOSE}=.046$, which suggests that the proposed model fits the data better.

\section{Discussion}

The purpose of this study was to investigate whether autonomy, competence, and relatedness could be viewed as determinants of HP and OP in athletes with disabilities, consequently resulting in life satisfaction. Results showed positive and significant associations between competence, relatedness and HP, while autonomy satisfaction was associated with OP. However, only HP was significantly associated with life satisfaction. These results were obtained while statistically controlling for each need and the number of training sessions.

\section{Needs satisfaction and passion}

Based on bivariate correlations, all three needs were associated with HP. However, regression analyses suggest that competence and relatedness may be more important for Paralympians to feel higher levels of HP. These results are somewhat comparable to those reported by Lalande et al., ${ }^{7}$ where needs satisfaction as a composite score in the passionate activity was significantly associated with HP. These results also support the hierarchical model of intrinsic and extrinsic motivation, ${ }^{31}$ which posits that one's needs satisfaction in one life context influences internalized and autonomous processes in this context's activities. Hence, Paralympians who experience a greater sense of competence and relatedness within their sport practice also seem to display greater HP towards the activity itself.

Current findings also suggest that Paralympians do not engage in sport as an obsessive response to needs satisfaction. In fact, correlations showed that only relatedness and autonomy were positively associated with OP. Path analyses further suggested that autonomy may be more important for the experience of OP as it was the only need that displayed a significant 


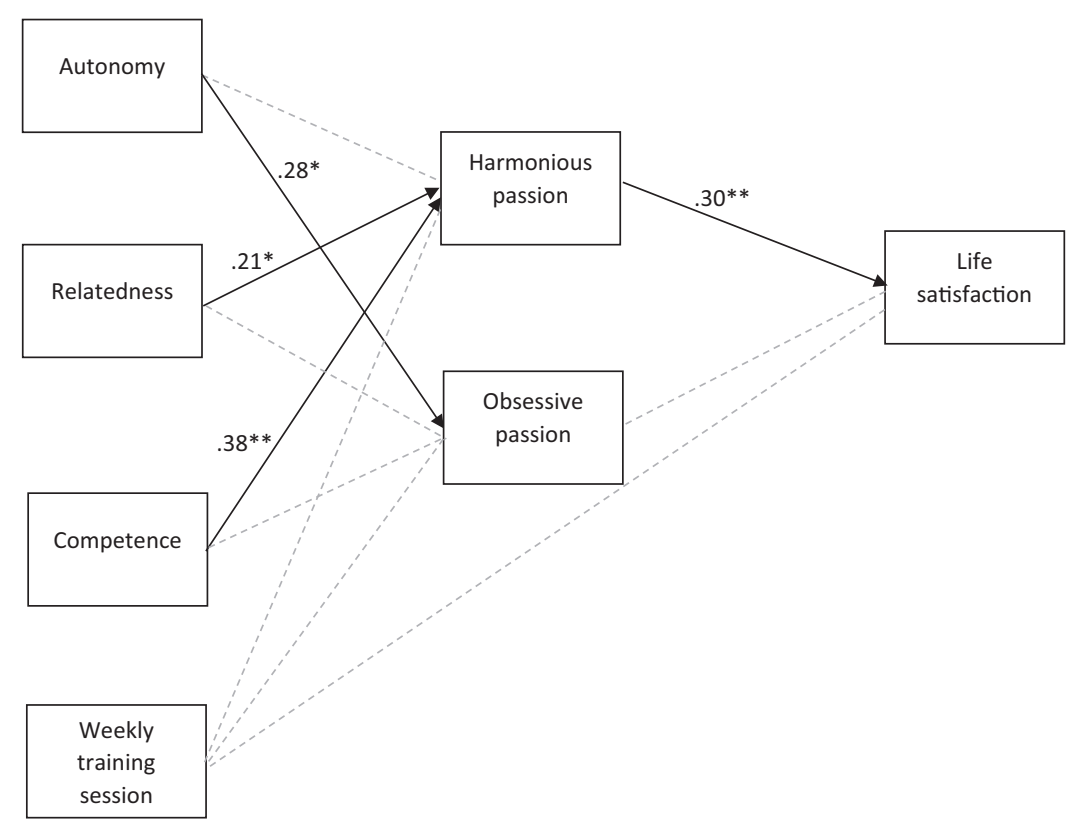

Figure I. Proposed model. Notes. ${ }^{*} p<.05,{ }^{*} p<<.0$ I.

association with OP when controlling for the other needs and the number of training sessions. In line with Lalande and his colleague's findings, ${ }^{7}$ we hypothesize that Paralympians who have developed OP may perhaps experience higher levels of autonomy within their sport compared to other contexts and social environments. Such sharp contrasts in autonomy experiences could in turn make athletes rely on their sport activity to compensate for autonomy deprivations in other life domains. This may hold true since athletes with disabilities face daily challenges that could compromise autonomy. During sport participation, however, they may feel an increased sense of volition and autonomous engagement, which in turn may place them at risk of overvaluing their sport and developing OP. To test Lalande and his colleagues' compensatory hypothesis, ${ }^{7}$ future research should assess Paralympian autonomy perceptions in other activities or social domains (e.g., family, friends, artistic activities) in addition to their autonomy perceptions within their sports.

Another possible explanation for this result is that while autonomy is necessary to develop any type of passion, athletes who develop OP may also experience instances of needs thwarting within their sport ${ }^{7}$ or other passionate activity. ${ }^{14}$ Future research should thus revisit the link between needs satisfaction and OP but this time while assessing both needs satisfaction and needs thwarting. Assessing needs thwarting could perhaps explain why other research has reported a negative association between needs satisfaction and OP. ${ }^{14}$

\section{Passion and life satisfaction}

Current associations between the two types of passion and life satisfaction suggest that OP may be compensatory in nature as it was found to be unrelated to life satisfaction. OP is generally considered as a less desirable form of passion because it entails a more controlled form of internalization of the activity in one's identity. ${ }^{15}$ In contrast, HP was positively and significantly related to this adaptive outcome, thereby supporting its role in experiencing a full and meaningful life. $^{32}$ The present findings also suggest that Paralympian's life satisfaction could be added to the list of adaptive processes that are associated with HP in the sport context. Such optimal functioning may also lead to peak experiences, such as increased sport performance and persistence, ${ }^{15}$ presumably because HP results from a more autonomous internalization of the passionate activity. ${ }^{15}$ Compared to OP, HP has been consistently linked to more adaptive outcomes across a variety of contexts ${ }^{13}$ and the current study shows that HP also predicts life satisfaction of Paralympians. These additional findings provide further support to the notion that increasing athlete HP contributes to their psychological well-being. ${ }^{33}$

\section{Mediating role of passion}

Although previous studies ${ }^{33}$ have shown that motivation mediates the effects of needs on several outcomes such as enjoyment and well-being, this study is the first to show that HP could serve the same function in Paralympic sports. First, analyses reveal that the 
proposed model fits the data better than the alternative model, thereby suggesting that passion could be the mediator between needs satisfaction and life satisfaction rather than need satisfaction mediating the association between passion and life satisfaction. These findings are in line with Lalande et al. ${ }^{7}$ results.

Only two significant indirect effects were observed. Paralympians' need for competence and relatedness were found to positively predict HP, which in turn was related to life satisfaction. These findings suggest that athletes who experience a sense of mastery and social bounding with others (e.g., peers, coaches), look harmoniously at sport practice and experience greater life satisfaction in general. Competence and relatedness within their sports could thus contribute to Paralympians' optimal functioning at a more global level. ${ }^{34}$ Yet, autonomy perceptions did not present a significant indirect effect on life satisfaction. Passion thus seems key to understand why deeply connected and autonomous athletes could at times report lower life satisfaction; they may be experiencing a more obsessive passion, which in turn prevents them from deriving life satisfaction from their need satisfaction.

\section{Strengths, limitations and future research directions}

Even though the current study produced some interesting insights on the mediation role of passion, certain limitations should be acknowledged. First, the present study was conducted with a relatively small sample. Although the sample was large enough to achieve adequate statistical power and collecting data from targeted samples such as Paralympians presents additional difficulties and barriers, a larger sample size may have yielded greater external validity. Moreover, the special context in which athletes with disabilities play sport might be too specific for the obtained results to be extended to a standard population of athletes or to other disciplines such as humanities and sciences. Nevertheless, this sample allowed us to create new knowledge on the role of need satisfaction and passion on life satisfaction, two aspects that may at times be overlooked by coaches and practitioners.

Second, results were obtained using the Portuguese 8 -item version of the Passion Scale, ${ }^{24}$ which slightly differs from the original 12-item version. Although the 8-item version of the Passion scale yielded better psychometric properties than the 12 -item version in a Portuguese context, ${ }^{24}$ the unexpectedly low correlation between HP and autonomy perceptions that was observed could perhaps be partly due to slight differences in the Passion Scale's items. Future research could reexamine the factor structure of the Passion scale in the Portuguese context but this time using the 12-item Passion Scale based on the Vallerand et al. ${ }^{9}$ work.

Third, whilst the current findings broaden our knowledge on the mediation role of passion between needs satisfaction and life satisfaction, the present study represents a small step toward the prediction of Paralympics' life satisfaction as the cross-sectional design prevents any causal inferences and formal tests of mediational hypotheses. Longitudinal studies are now needed to monitor how needs satisfaction, passion and life satisfaction evolve over time and whether changes in passion actually mediate long-term associations between needs satisfaction and life satisfaction.

Last, more research is needed to adequately describe the motivational patterns between needs and passion. Measuring both needs satisfaction and needs frustration within the passionate activity and in other life domains seems particularly important to shed light on the positive association between autonomy and $\mathrm{OP}$, which is contrary to past findings. ${ }^{14}$ Given that needs satisfaction and needs frustration act as orthogonal constructs, it may be that experiencing autonomy from some aspect of one's sports, while feeling controlled by other aspects, could set the stage for the development of OP. In line with Lalande et al. ${ }^{7}$ findings, Paralympians could also experience more needs satisfaction within their passionate activity compared to other life domains, which could result in compensatory mechanisms and consequently a more obsessive form of passion.

\section{Practical implications}

The present research has several implications for sport coaches involved in Paralympic competitions. First, our findings suggest that passion is an inherent part of being an Olympic athlete, and Paralympians are no exception. Means on HP and OP were indeed high, suggesting that most athletes could be considered highly passionate towards their sports. In fact, results show that these Paralympic athletes report higher levels of passion towards sport participation compared to regular athletes. ${ }^{8,18,22}$ Second, it seems that promoting competence and relatedness in athletes could be key to foster HP towards sport and in turn, life satisfaction. Coaches could increase competence by providing effective and timely inputs that assist athletes with mastering skills or knowledge, emphasizing accomplishments, and providing corrective instructions. ${ }^{35}$ Satisfying the need for relatedness also seems to be important because Paralympians' desire to belong and to feel connected could be a potent contributor to the development of HP. Coaches could strengthen connections between all team members by making sure that formal and informal meetings occur on a regular basis. Finally, 
although future research is needed to understand the exact link between autonomy and OP, it may still be warranted to highlight the importance of autonomy for the development of passion. Past findings have documented a positive association between autonomy support and $\mathrm{HP}^{16}$ and a large body of research suggests that autonomy support is associated with positive sport outcomes. ${ }^{36}$ Together, these findings suggest that support for competence and relatedness may be more beneficial within more autonomy-supportive social environments.

\section{Conclusion}

In sum, the present study provides additional support for the mediating role of HP in the relation between needs satisfaction and life satisfaction as well as demonstrates the unique importance of HP for Paralympians' life satisfaction. Coaching in a needsupportive way and promoting HP could help Paralympic athletes persist in highly demanding competitions in a way that promotes life satisfaction. Further research is however needed to increase knowledge on the processes linking need-supportive behaviors, basic psychological needs, passions, and life satisfaction in the context of sport.

\section{Declaration of conflicting interests}

The author(s) declared no potential conflicts of interest with respect to the research, authorship, and/or publication of this article.

\section{Funding}

The author(s) disclosed receipt of the following financial support for the research, authorship, and/or publication of this article: This work was supported by the National Funding through the Portuguese Foundation for Science and Technology, I.P., under the project UIDP/04748/2020 for the author Filipe Rodrigues; and under the project UID04045/2020 for the author Diogo Monteiro and Luís Cid.

\section{ORCID iDs}

Filipe Rodrigues (D) https://orcid.org/0000-0003-1327-8872 Diogo Monteiro (D) https://orcid.org/0000-0002-7179-6814

\section{References}

1. Kleszczewska D, Dzielska A, Salonna F, et al. The association between physical activity and general life satisfaction in lower secondary school students: the role of individual and family factors. Community Ment Health $J$ 2018; 54: 1245-1252.

2. Peters D, Smith K and Solomonides I. Exploring the development of passion in paralympic athletes. Learn Teach 2015; 8: 55-71.
3. Martin J. Handbook of disability sport \& exercise psychology. New York: OUP, 2018.

4. Vallerand $\mathrm{R}$ and Verner-Filion J. Theory and research in passion for sport and exercise. In: Tenenbaum $G$ \& Eklund R (ed) Handbook of sport psychology. 4th ed. Hoboken: Wiley, 2020. pp. 206-229.

5. Diener E. Subjective well-being. The science of happiness and a proposal for a national index. Am Psychol 2000; 55: 34-43.

6. Ryan R and Deci E. Self-determination theory. Basic psychological needs in motivation, development, and wellness. New York: Guildford Press, 2017.

7. Lalande D, Vallerand RJ, Lafrenière $\mathrm{MK}$, et al. Obsessive passion: a compensatory response to unsatisfied needs. J Pers 2017; 85: 163-178.

8. Lopes $\mathrm{M}$ and Vallerand $\mathrm{R}$. The role of passion need satisfaction, and conflict in athletes' perceptions of burnout. Psychol Sport Exerc 2020; 48: 101674.

9. Vallerand RJ, Blanchard C, Mageau GA, et al. Les passions de l'ame: on obsessive and harmonious passion. J Pers Soc Psychol 2003; 85: 756-767.

10. Vallerand R. On passion for life activities: the dualistic model of passion. In: Zanna M (ed) Advances in experimental social psychology. Cambridge: Academic Press, 2010, pp. 97-193.

11. Mageau G, Carpentier J and Vallerand R. The role of self-esteem contingencies in the distinction between obsessive and harmonious passion. Eur J Soc Psychol 2011; 41: 720-729.

12. Rip B, Fortin $\mathrm{S}$ and Vallerand $\mathrm{R}$. The relationship between passion and injury in dance students. $J$ Dance Med \& Sci 2006; 10: 14-20.

13. Curran T, Hill A, Appleton P, et al. The psychology of passion: a meta-analytical review of a decade of research on intrapersonal outcomes. Motiv Emot 2015; 39: 631-655.

14. Tóth-Király I, Bőthe B, Márki A, et al. Two sides of the same coin: the differentiating role of need satisfaction and frustration in passion for screen-based activities. Eur J Soc Psychol 2019; 49: 1190-1205.

15. Vallerand R. The psychology of passion: a dualistic model. Oxford: Oxford University Press, 2015.

16. Mageau G, Vallerand $R$, Charest $J$, et al. On the development of harmonious and obsessive passion: the role of autonomy support, activity specialization, and identification with the activity. J Pers 2009; 77: 601-646.

17. Bonneville-Roussy A, Vallerand R and Bouffard T. The roles of autonomy support and harmonious and obsessive passions in educational persistence. $J$ Individ Differ 2013; 24: 22-31.

18. Chamorro J, Moreno R, García-Calvo T, et al. The influence of basic psychological needs and passion in promoting elite young football players' development. Front Psychol 2020; 11: 570584.

19. Sheldon K and Niemiec C. It's not just the amount that counts: balanced need satisfaction also affects well-being. J Pers Soc Psychol 2006; 91: 331-341.

20. St-Louis A, Rapaport M, Chénard Poirier L, et al. On emotion regulation strategies and well-being: the role of passion. J Happiness Stud 2021; 22: 1791-1818. 
21. Marsh H, Vallerand $\mathrm{R}$, Lafrenière $\mathrm{M}$, et al. Passion: does one scale fit all? Construct validity of two-factor passion scale and psychometric invariance over different activities and languages. Psychol Assess 2013; 25: 796-809.

22. Kent S, Kingston K and Paradis K. The relationship between passion, basic psychological needs satisfaction and athlete burnout: examining direct and indirect effects. J Clin Sport Psychol 2018; 12: 75-96.

23. Monteiro D, Marinho D, Moutão J, et al. Adaptation and validation of the Portuguese version of basic psychological needs exercise scale (BPNESp) to the sport domain and invariance across football and swimming. Motricidade 2017; 12: 51.

24. Cid L, Vitorino A, Bento T, et al. The passion scale Portuguese version: reliability, validity, and invariance of gender and sport. Percept Mot Skills 2019; 126: 694-712.

25. Neto F. Life satisfaction scale: psychometric properties in an adolescent sample. J Youth Adolescence 1993; 22: 125-134.

26. Gravetter F and Wallnau L. Essentials of statistics for the behavioral sciences. 8th ed. Belmont: Cengage Learning, 2014.

27. Arbuckle J. IBM SPSS and AMOS 22 user guide, IBM, 2015.
28. Browne M and Cudeck R. Alternative ways of assessing model fit. Sociol Methods Res 1992; 21: 230-258.

29. Tabachnick B and Fidell L, Using multivariate statistics. 6th ed. London: Pearson, 2013.

30. Cohen J. Statistical power analysis for the behavioral sciences. Hillsdale: Lawrence Erlbaum Associates, 1988.

31. Vallerand R. Toward a hierarchical model of intrinsic and extrinsic motivation. Add J Exp Psychol 1997; 29: 271-360.

32. Vallerand R, Mageau G, Elliot A, et al. Passion and performance attainment in sport. Psychol Sport Exerc 2008; 9: 373-392.

33. Vallerand R. The role of passion in sustainable psychological well-being. Psychol Well-Being Theory Res Pract 2012; 2: 1-21.

34. Vallerand R, Rousseau F, Grouzet F, et al. Passion in sport: a look at determinants and affective experiences. J Sport \& Exerci Psycho 2006; 28: 454-478.

35. Carpentier J and Mageau G. The role of coaches' passion and athletes' motivation in the prediction of changeoriented feedback quality and quantity. Psychol Sport Exerc 2014; 15: 326-335.

36. Mageau $\mathrm{G}$ and Vallerand $\mathrm{R}$. The coach-athlete relationship: a motivational model. J Sports Sci 2003; 21: 883-904. 